\title{
THE RELATIONSHIP BETWEEN GENERAL HEALTH, OCCUPATIONAL STRESS AND JOB BURNOUT IN NURSES WORKING SHOHADAYE KARGAR HOSPITAL OF YAZD
}

\author{
Khabazzadeh Fatemeh ${ }^{1}$, Nimetcan Mehmet $^{2}$ and Alabed Ali A. Alabed ${ }^{3}$ \\ ${ }^{1}$ Faculty of Medicine, Islamic Azad University, Yazd, Iran \\ 2 Department of Public Health, Faculty of Medicine, Ankara Yildirim Beyazit University, Turkey \\ ${ }^{3}$ Community Medicine Departmenti Faculty of Medicine, Lincoln University College, Malaysia
}

Corresponding Author: Alabed Ali A. Alabed

Email: abed11k@gmail.com

\begin{abstract}
Aim of this study is to determine levels of general health, occupational stress and burnout in nurses who are working in Shohadaye Kargar Hospital of Yazd. A cross- sectional study was conducted among nurses who are working in Shohadaye Kargar Hospital of Yazd in 2017-2018 years. The sample was randomly selected and total 200 nurses were enrolled to the study. The study instruments included Occupational stress questionnaire, Maslach Burnout Inventory and General Health Questionnaire. Collected Data were analyzed by using descriptive test and Pearson correlation coefficient and multivariate regression in SPSS. The findings of research indicated that total levels of occupational stress were high among $58.85 \%$ of nurses. Regarding burnout, 35.93\% of nurses had reported high levels of burnout. Less than one percent $(0.37 \%)$ of nurses have high mental health problems and 0.44 percent reported mid mental health problem. There was a statistically significant correlation between occupational stress with mental health $(p<.001)$ and job burnout with mental health $(p<.001)$. Occupational stress and job burnout may have undesired influences on nursing mental health and general function.
\end{abstract}

Key words: occupational stress, job burnout, general health

\section{INTRODUCTION}

Job for every person is one of the most underlying sources of occupational tension ${ }^{1}$. Nurses form the largest manpower resource of health system almost in all countries of the world and play key role in social health promotion ${ }^{2}$. Nurses can form one of groups with highest job stress experience 3 . In nursing, from the time of education to the time of retirement, the nurses tolerate many ups and downs. Working shifts, working for more than 1 shift during $24 \mathrm{hr}$, compulsory overtime are factors affecting job satisfaction of individuals ${ }^{4}$.

Longtime job stress can lead to job burnout ${ }^{5}$. Jobs like nursing with high stress and low control can cause mental and physical distress. Finally, psychological and emotional resources of nurses are drained, and the way is paved for beginning of job burnout syndrome ${ }^{6}$. Many scholars believe that prevalence of job burnout in nursing profession is everyday encountering with stressful situations ${ }^{1}$. Because of nature of nursing with encompasses communicating patients and caregiving for them, negligence of recognition and coping with these stresses can cause irreparable complications ${ }^{7}$. Decline of caregiving quality can be the worst outcome of job burnout in nurses. When a nurse is burned out, patients are deprived from getting sufficient care and the individuality and human rights are questioned ${ }^{8}$. This is because; at the current modern world, the issue of job burnout of nurses, weakness of performance, hospital events, inefficiency of nurses against safety of patients and their low commitment to organization happen most of the time ${ }^{7}$. At hospitals, the percentage of accidents is being increased day by day, the commitment of nurses to organization and assets and properties is decreased and the performance of some nurses is weakened as time goes. As it is obvious, all of the mentioned issues are associated with job stress ${ }^{6}$. Unconsciously, the stresses and job dissatisfactions caused by the stresses also affect personal life easily and can decrease mental health and ultimately, their mental well-being ${ }^{9}$.

Moreover, job stress within organizations was considered by scholars of management and psychology and issues such as health, human values, safety, anxiety, failure, frustration, mental stress, professional silence and feeling failure were presented ${ }^{10}$. Job stresses correlated to mental health, emotional health and effectiveness of employees ${ }^{11}$. The outcomes of job stress and importance of considering what can be necessities of conducting study in this field. The today's job tension has been changed into common and costly problem in work places and a few people have not encountered that. The scientists of medical sciences believe that considerable percentage of mental and physical diseases caused by job are attributed to excessive stress. Although this is not the only harm, it can also affect performance significantly. Tuithof believes in the discussion on neural stresses that 
neural stresses can affect the performance and activity of organizational members and can cause special mental modes for them and they may show behaviors and actions, which can be reflected in the efficiency of organization. As a result, human resource is wasted and the organizational goals are collapsed ${ }^{12}$.

In this regard, effectiveness of job stress and job burnout on mental health of individuals is evident 3. This is because; mental health is one of the most important results of a right and good choice in job selection, which can provide adaptability with work, possibility of creativity, satisfying relations with partners and increasing self-esteem 13. On the contrary, job inadaptability is an issue causing repetitive change of job, absence, job and self-dissatisfaction, sense of insecurity and anger and hatred of job ${ }^{14}$. In view of World Health Organization ${ }^{15}$, mental health is complete physical, mental and social health. Mental health is a concept showing the quality of feeling, thinking and performance of individuals in encountering life situations and is depended on understanding of person of self and life. Moreover, depending on the amount of mental health, the performance in controlling stress, communicating others, assessments and choices are different ${ }^{16}$. Mental health shows the health status of people in terms of physical and mental status and weakness in that can be specified with physical symptoms, anxiety and sleep disorder, disruption in social action and major depression 12 .

Cheung (2016) conducted a study to analyze the prevalence of depression, anxiety and stress symptoms in nursing department in Hong Kong. The recent epidemiologic data show that prevalence of mild to major depression, anxiety and stress in qualified nurses in Hong Kong was respectively obtained to $35.8 \%, 37.3 \%$ and $41.1 \%$. In general, 661 nurses filled out the mental health questionnaire using depression, anxiety and stress scale ${ }^{17}$. To determine the correlation between variables, multivariate logistic regression was used. Working in nursing domain, financial problems, sleep disorders, leisure time activities and self-understanding in weak mental health was in significant correlation with depression, anxiety and stress of past times. The educational year, lack of physical activity and family crisis in last year was significantly correlated to depression. Stress could significantly affect mental health problems. They found that this is the first study confirming empirically that clinical symptoms, financial problems and lifestyle factors can increase depression, anxiety and stress symptoms of nurses. In another study, Spence (2017) showed that nurses as a group are highly vulnerable against job burnout ${ }^{18}$. This is because; the job can lead to high job burnout because of high stress, high organizational expectations, high emotional expectations of patients, high workload, change in work shifts, sleep disorders and playing different roles.

In Iran, the study conducted by Moghali et al (2015) on analysis of the correlation between job satisfaction and job burnout between nurses in private and public sector and found that there is negative significant correlation between the two variables in public sector ${ }^{19}$. This is because; in public hospitals, based on low medication costs, number of patients is more than private sector and nurses in this sector tolerate high workload; although in private sector, as policy making was out of authority of the government and the owners and stockholders search for more interest to support their forces and take effort to satisfy them; this can lead to decreased job burnout in them and in discrimination of these results, it could be mentioned that organizations using motivational factors to enhance job satisfaction of employees have lower level of job burnout and higher performance efficiency. Moradi et al (2014) conducted some studies in field of as people playing key role in rescuing life of people and identified the amount and risk of job burnout in the personnel. The study showed that operating personnel of pre-hospital emergency in Isfahan reported average degrees of intensity and times of feeling emotional exhaustion, depersonalization and highly sense of personal inefficiency ${ }^{20}$. Elsewhere, Moradbeigi et al (2013) mentioned that job burnout is one of the main unavoidable outcomes of job stress and decline of quality of caregiving by nurses ${ }^{21}$.

According to the differences among previous studies on the job stress level and job burnout and because of lack of a study analyzing the correlation of these variables with general health problems in nurses employed in Shohada Kargar Hospital in Yazd; this study has attempted to determine the correlation between general health and job burnout in nurses employed in Shohada Kargar Hospital in Yazd.

\section{METHOD}

\section{Study design and sample}

A cross- sectional study was conducted among nurse who are working in different department in Shohada Kargar Hospital in 2017-2018. The sample size was obtained according to Abdi (2017) study 22 and taking into account the test power $80 \%, a=0 / 05$, the effect size 0.079 and the three predictor variables of 200 people. The sample was selected randomly and total 200 nurses were selected from the hospital. Inclusion criteria in this study are; at least one-year work experience, degree of BA in Nursing and Exclusion criteria included having a history of mental illness and being treated and unwillingness to participate in 
the

$N \geq\left(\frac{2-2 \rho^{2}+\varepsilon}{\varepsilon}\right)(K+1)$

$\varepsilon=0.2 \rho^{2}$

\section{Study instrument}

The instrument includes sociodemographic information of the participants, occupational stress inventory (OSI), Maslach Burnout Inventory $(\mathrm{MBI})$ and general health questionnaire (GHQ). The occupational stress inventory (OSI) contains 40 items in 5-point Likert scale and the scoring was determined from summation of items and dividing them in 3 levels of low (0-54), intermediate (55-108) and high (109-160). The internal reliability of this questionnaire was determined using Cronbach's alpha coefficient of 0.82

Maslach Burnout Inventory (MBI) contains 22 items pointed in 7-point Likert scale and 0 means never and 6 means every day. There were 9 items on emotional exhaustion, 5 items on depersonalization and 8 items were on personal efficiency. The obtained value was placed in 3 levels including low, intermediate and high level. The range of scores for subscale of emotional exhaustion was $0-54$; in range $0-30$ for depersonalization and to $0-48$ for personal efficiency. Job burnout can be diagnosed if emotional exhaustion and depersonalization have gained high score and personal efficiency has gained low score. Maslach and Jackson (2013) reported internal consistency of questionnaire in range 0.71-0.91 and internal consistency of each subscale of emotional exhaustion $(r=0.9)$, depersonalization $(r=0.79)$ and personal efficiency $(r=0.71)$ in favorable level. Scientific validity of the questionnaire was reported to 0.90 ${ }^{23}$. In the studies in Iran, validity and reliability of the questionnaire was obtained significant, so that in the study of Sharifi (2006), reliability of the questionnaire was obtained to 0.68. Mellati and Raeisifar (2014) reports convergent validity of the questionnaire (AVA) to 0.83 and reliability of $0.94^{24}$.

General health questionnaire (GHQ-28) as a screening instrument can determine the probability of existence of a mental disorder in person. The said questionnaire has high validity and reliability. Moreover, it includes implementation method, scoring and table relevant to interpretation of values ${ }^{25}$. More than 70 studies have been conducted on validity of this scale till now and Goldberg (1988 presented metaanalysis of these studies and found that average sensitivity of the GHQ-28 is equal to $84 \%$ (range $775-89 \%)$ and average feature of that was equal to $82 \%$ (range $78 \%-85 \%)^{26}$. In the study conducted by Besharat (2009) under the title of correlation between tenacity and its components with general health of students; GHQ was validated using total number of revised lists of mental symptoms (SCL-90-R). Reliability coefficient was reported for 4 domains respectively to $86 \%, 85 \%$, $72 \%$ and $82 \%{ }^{26}$.

\section{Data analysis}

Data analysis was done using descriptive statistics (frequency, frequency percentage, mean, standard deviation, minimum and maximum) and for the results of statistical tests, KolmogorovSmirnov test was used to evaluate the normality of research variables. And then multiple regression was used in SPSS 18.

\section{RESULTS}

Table 1 shows the frequency distribution of nurses in terms of demographic variables

Table 1: Socio- demographic information of participants

\begin{tabular}{llll}
\hline Variables & & Frequency & Percent (\%) \\
\hline \multirow{2}{*}{ Age } & $20-30$ years old & 38 & 19.10 \\
& $31-40$ years old & 124 & 61.79 \\
Marital status & $41-50$ years old & 31 & 15.38 \\
& Above 50 years old & 7 & 3.73 \\
Gender & Married & 131 & 65.62 \\
& Single & 69 & 34.38 \\
Work experience & Female & 122 & 61.2 \\
& Male & 78 & 38.8 \\
& $1-10$ years & 7 & 3.38 \\
& $11-20$ years & 118 & 59.34 \\
\hline
\end{tabular}

The findings in Table 1 show majority of nurses (68.79) were in age range of 31-40 years old,
$61.2 \%$ of them were female, $65.62 \%$ were married and $59.34 \%$ had work experience of $10-20$ years. 
Malaysian Journal of Public Health Medicine 2020, Vol. 20 (3): 173-179

Table 2: Sseverity of job stress, burnout and general health of participants

\begin{tabular}{|c|c|c|c|c|c|c|c|}
\hline \multicolumn{2}{|c|}{ severity of dimensions } & \multicolumn{2}{|l|}{ Low } & \multicolumn{2}{|l|}{ Average } & \multicolumn{2}{|l|}{ High } \\
\hline variables & & Frequency & Percent & Frequency & Percent & Frequency & Percent \\
\hline & Contradiction in function & 77 & 38.7 & 72 & 35.9 & 51 & 25.4 \\
\hline & Overload of duties & 10 & 4.7 & 52 & 26.3 & 138 & 69 \\
\hline Dimensions & Responsibility & 10 & 5.2 & 34 & 16.5 & 156 & 78.3 \\
\hline \multirow{3}{*}{ of job stress } & Physical environment & 18 & 8.9 & 57 & 28.4 & 125 & 62.7 \\
\hline & Total job stress level & 29 & 14.41 & 54 & 26.74 & 117 & 58.85 \\
\hline & Emotional exhaustion & 9 & 4.8 & 78 & 39.3 & 113 & 55.9 \\
\hline \multirow{4}{*}{$\begin{array}{l}\text { Job burnout } \\
\text { dimensions }\end{array}$} & Depersonalization & 135 & 67.4 & 56 & 28.2 & 9 & 4.4 \\
\hline & Personal efficiency & 21 & 10.3 & 84 & 42.2 & 95 & 47.5 \\
\hline & Total job burnout & 55 & 27.5 & 73 & 36.57 & 72 & 35.93 \\
\hline & Physical symptoms & 15 & 7.7 & 137 & 68.6 & 48 & 23.7 \\
\hline \multirow{4}{*}{$\begin{array}{l}\text { General } \\
\text { health } \\
\text { dimensions }\end{array}$} & Anxiety & 10 & 5.1 & 61 & 30.4 & 129 & 64.5 \\
\hline & Dysfunction & 96 & 48 & 60 & 30 & 44 & 22 \\
\hline & Social depression & 20 & 9.7 & 100 & 50.2 & 80 & 40.1 \\
\hline & General health problems & 35 & 17.62 & 90 & 44.8 & 75 & 37.58 \\
\hline
\end{tabular}

More than half of the of nurses $(58.8 \%)$ had high job stress. On different dimensions of job stress, $69 \%$ of nurses had stress due to workload, $78.35 \%$ of them due to job responsibility and $62.7 \%$ of them due to physical environment. In terms of job burnout, $35.93 \%$ of them reported high job burnout. $55.9 \%$ of them reported high emotional exhaustion and $47.5 \%$ of them reported high personal inefficiency. However, in terms of depersonalization, $67.4 \%$ of nurses reported low level. On general health problems, $37.58 \%$ of nurses reported high general health problems. In terms of dimensions of general health, $68.6 \%$ of them were in average level in terms of physical symptoms; $64.5 \%$ of them were in high level in terms of anxiety; $22 \%$ of them were in high level in terms of social function and $40 \%$ of them were in high level in terms of depression.

Table 3: Correlation between total burnout scores, general health and job stress of nurses

\begin{tabular}{llll}
\hline Variables & Job stress & general health & Burnout \\
\hline Job stress & - & $0 / 486$ & $0 / 349$ \\
general health & $0 / 486$ & - & $0 / 353$ \\
Burnout & $0 / 349$ & $0 / 353$ & - \\
\hline
\end{tabular}

Based on the findings of this study, there was a statistically significant relationship between all dimensions of burnout, general health and job stress. However, there was a statistically significant relationship between anxiety and depersonalization, depression and emotional exhaustion, between depression and depersonalization and depression and social functioning. not found.

\section{DISCUSSION}

The present study was a cross-sectional descriptive study that was performed on 200 nurses working in Shohada Kargar Hospital in Yazd. Data analysis showed that the highest percentage of units $(6.2 \%)$ were women, in terms of age the highest percentage of units $(68.79 \%)$ were in the age range of 31 to 40 years and in terms of work experience the highest percentage of units (59.34\%) had a history They worked for 10 to 20 years.

Findings showed that $69 \%$ of nurses mentioned high stress in terms of workload, $78.3 \%$ in terms of responsibility and $62.7 \%$ in terms of physical environment. Showed that physical environment and responsibility were the most important stressors in nurses. Regarding burnout, in which
$55.9 \%$ of the units reported high emotional fatigue, Payami's research on nurses showed that $39 \%$ of them had high burnout ${ }^{9}$.

Residents reported moderate burnout in three dimensions, which was not consistent with our study ${ }^{14}$. Moderate levels of burnout in the study units. Cabrera Gutierrez reported the rate of burnout among nursing staff, in various dimensions of emotional exhaustion, depersonalization and inefficiency, respectively, $40,32 \%$ and $63 \%$, respectively. The individual inefficiency dimension then reported that these findings are consistent with our findings. The feeling of success and mastery and the feeling of personal adequacy arise when a person can influence the policies of the respective organization and thereby show his abilities and show a positive attitude towards himself and his patients. Goal-finding has become more common in idealistic nurses ${ }^{6}$. Nurses' mental health is endangered compared to other sections of society for several reasons.

The most important of these reasons can be the stressful nature of the profession, work pressure, dealing with unexpected situations, work shifts, organizational factors as well as personal factors. On the other hand, as we know, the 
responsibilities that they are responsible for doing at work are also the responsibility of the home and children, and this in itself increases the level of anxiety and stress in this segment of society and puts their mental health at risk. Different numbers have been reported about the prevalence of mental health disorders in other parts of the world. Studies reported that main sources of the occupational stress were related to work environment, economic problem long work hours and problems related to worker's children 27,28 .

Gerald D, for example, reported a 34\%, 41\% Fagin, and $48.8 \%$ mei-song prevalence of mental health disorders among nurses. Regarding the dimensions of general health, in terms of physical symptoms, $68.6 \%$ mentioned moderate and $64.5 \%$ high anxiety. In this regard, Rahmani et al. (2009) found in their study $50.9 \%$ of nurses in terms of physical symptoms. Moderate and $62.7 \%$ reported high anxiety 29. Khajeh Nasiri (2000) found that $26.9 \%$ of nurses in intensive care units had significant depression ${ }^{30}$. As with increasing job stress, burnout also increased, which is in line with the results of Abdi and Rahmani's study.

Another result of this study is a significant relationship between job stress and general health, which is consistent with the results of the study by Chang et $\mathrm{al}^{31}$. In their study, they concluded that reducing environmental stress could improve nurses' mental health ${ }^{29}$. Nurse's poor sleep led to reduces their quality of life and general health perception, mental status and physical pain ${ }^{32}$. Also, the findings regarding the relationship between burnout and general health showed that the lower the burnout, the better the mental health. Nurses are higher which is consistent with the results of Payami ${ }^{9}$ Rahmani 29 and Moradbeigi ${ }^{20}$, Murad Beigi in his study showed that the general health of nurses is moderate. By taking measures to reduce burnout, their general health can be improved. In their study, Badri et al. Examined various aspects of general health, and according to their findings, $63 \%$ of the samples had high anxiety ${ }^{33}$. And $48 \%$ of the units had moderate physical symptoms, which recommended that by using strategies to reduce stress and burnout, nurses' mental health could be improved and the quality of nursing care could be increased. Rahmani also showed a significant relationship between job stress and general health in his study ${ }^{29}$.

The findings of this study can be of great importance. Burnout imposes many consequences and costs on the organization as well as on the physical and mental health of the staff. Of course, these effects on medical staff have adverse effects on proper patient care. Significant prevalence of mental health disorders also requires a significant prevalence of burnout after individual performance, especially among younger staff with less work experience. These interventions can be called organizational interventions. Many researchers believe that these interventions, such as encouraging teamwork, involving staff in decision-making, job support, reducing conflict and job ambiguities, and increasing control over work-only and nonwork-related mental health events, are also positive. It should be done in the workplace, but their training and, of course, seems to be part of the training programs of health care personnel. In the case of a group with severe mental health problems or severe burnout, specialized individual interventions are needed.

The results of the research can be used as a source of information and statistics for the planning of university officials involved in mental health programs. This study can also be used as a study to evaluate the effectiveness of interventions that will be performed to reduce burnout. Providing psychiatric and psychological counseling centers at the hospital level for staff, teaching adaptive methods and mechanisms of adaptation to health care personnel before entering the workplace, providing retraining courses to reduce the increase in brightness. Since fatigue could affect the completion of the questionnaires, so we tried to complete the questionnaires at times when the workload of nurses is less. But issues such as insomnia and lack of rest of the nurse during the past days, family and personal issues and problems of the nurse that could affect the response were not in the hands of the researcher. The researcher also did not have the honesty of the units in expressing the history of mental disorders or diseases such as depression before entering the nursing profession. The researcher also did not have the honesty of the units in expressing the history of mental disorders or diseases such as depression before entering the nursing profession.

\section{CONCLUSION}

Overall job stress is high $(58,9 \%)$ among the nurses in the hospital, the job stress due to overload of duties, job responsibility and physical environment. Around a quarter (35.93\%) of nurses reported high job burnout and $37.58 \%$ of nurses reported high general health problems. there is significant correlation between general health, job stress and burnout.

Conflicting Interest: There is no conflict interest Funding: There is no funding for the study

\section{REFERENCES}

1. Brough $\mathrm{P}$, Drummond $\mathrm{S}$ and Biggs $\mathrm{A}$. Assessment of simultaneous impacts within the occupational stress process. Journal of occupational health psychology.2018; 23(2): 188. 
2. Cheung $T$ and et al. Depression, anxiety and symptoms of stress among baccalaureate nursing students in Hong Kong: a cross-sectional study. International journal of environmental research and public health. 2016; 13(8): 779.

3. Dreison K.C and et al. Job burnout in mental health providers: A meta-analysis of 35 years of intervention research. Journal of occupational health psychology. 2018; 23(1): 18.

4. Elshaer N.S.M and et al. Job stress and burnout syndrome among critical care healthcare workers. Alexandria Journal of Medicine. 2018; 54(3): 273-277.

5. Ford M.T and et al. How do occupational stressor-strain effects vary with time? A review and meta-analysis of the relevance of time lags in longitudinal studies. Journal: Work \& Stress. 2014; 28(1): 9-30.

6. Gutsan E, Patton J, Willis W.K and et al. Burnout syndrome and nurse-to-patient ratio in the workplace. Presented at the 54th Annual MBAA Conference, Chicago, IL. 2018.

7. Khamisa N, Peltzer K, Llic D,Olden berg. Effect of personal and work stress on burnout, job satisfaction and general health of hospital nurses in South Africa. health sa gesondheid. 2017; 22(1): 252258.

8. Lawless J, Wan L, Zeng I. Patient care'rationed'as nurses struggle under heavy workloads. Nursing New Zealand (Wellington, NZ: 1995). 2010; 16(7): 1618.

9. Payami M. The study of social support and its relation with burnout of critical nurses. J Zanjan Univ Med Sci Health Serv. 2001; 32(3): 52-56.

10. Sawatzky J, A.V. Stress in critical care nurses: actual and perceived.Journal: Heart \& Lung. $\quad 1996$; 25(5): 409-417.

11. Scheibe S, Zacher $H$. A lifespan perspective on emotion regulation, stress, and well-being in the workplace, in The role of emotion and emotion regulation in job stress and well being. Publisher: Emerald Group Publishing limited.2013;11(3).

12. Tuithof $M$, Have $M$,Beekman A and et al. The interplay between emotional exhaustion, common mental disorders, functioning and health care use in the working population. Journal of psychosomatic research. 2017; 100: 8-14.

13. Zadow A.J, Dollard F.M,Mclinton S.S and et al. Psychosocial safety climate, emotional exhaustion, and work injuries in healthcare workplaces. Stress and Health. 2017;33(5): 558-569.

14. Staal J, Collier L, Homel P. Multisensory Environmental Therapy (Snoezelen) for Job Stress Reduction in Mental Health Nurses: a Randomised Trial. International Journal of Complementary \& Alternative Medicine. 2018;11(1):49-54.

15. World health organization. Core competencies in adolescent health and development for primary care providers.https:// www. who.int/ a dolescent health/ development component/ health care providera. Accessed on $16^{\text {th }}$ March 2015.

16. Shahrokhi A, Elikaei N, Yekefallah L, Barikani A. Relationship between spiritual intelligence and perceived stress among critical care nurses. The Journal of Qazvin University of Medical Sciences. 2018; 22(3): 40-49.

17. Cheung $T$ and et al., Depression, anxiety and symptoms of stress among baccalaureate nursing students in Hong Kong: a cross-sectional study. International journal of environmental research and public health. 2016;13(8): 779.

18. Boamah S.A, Read E.A and Spence H.K. Laschinger, Factors influencing new graduate nurse burnout development, job satisfaction and patient care quality: a time-lagged study. Journal of advanced nursing.2017;73(5): 1182-1195.

19. Mooghali A , Habibi H, Ahmadi M, Habibi F. Relationship Between Job Satisfaction and Burnout Among Nurses in Public and Private Hospitals in Shiraz City in 2012. Journal:Hospital.2015;14(3):119-126.

20. Moradi Z, Eslami A.A and Hasanzadeh A. Assessment of burnout status in prehospital emergency operating personnel. Iranian Journal of Emergency Medicine.2014; 2 (1): 28-32.

21. Zanganeh and et al. The study of burnout and its relationship with general health of nurses working in Abadan and 
Khorramshahr hospitals in 2012. Scientific Research Journal of Ilam University of Medical Sciences. 2014; 22 (4): 217-224.

22. Abdi H, Shahbazi L. Correlation between occupation stress in nurses at intensive care unit with job burnout. JOURNAL OF SHAHID SADOUGHI UNIVERSITY OF MEDICAL SCIENCES AND HEALTH SERVICES .2001;9(3): 58-63.

23. Maslach C, Jackson S.E. Manual of the Maslach Burnout Inventory. 2nd ed. Palo Alto: Consulting Psychologists Press Inc. 1993.

24. Raeisifar K, Melati A. The role of positive $\mathrm{OB}$ in preventing job pathologies: investigating the relationship between PsyCap and Job Burnout. Journal of public administration.2014; 6(4): 705-723.

25. Maslach C, Jackson S.E. Manual of the Maslach Burnout Inventory. 2nd ed. Palo Alto: Consulting Psychologists Press Inc. 1993.

26. Basharat M. Reliability and validity of the 28-item form of mental health scale in iranian population. Journal of Legal Medicine. 2009; 15(2): 78-91.

27. Masoud Lotfizadeh, Namaitijiang Maimaiti, Noor Hassim Ismai. Occupational Stress Among White Collar Employees in Esfahan Steel Company, Iran. Malaysian Journal of Public Health Medicine 2014, Vol. 14 (1): 79-81.

28. Mohd Shaiful Azlan Bin Kassim, Aniza Ismail and Rosnah Ismail. A Review of Occupational Stress Prevalence and Its Predictors Among Selected Working Populations in Malaysia.

29. Rahmani Fand et al. Relationship between general health, occupational stress and burnout in critical care nurses of Tabriz teaching hospitals. Iran Journal of Nursing. 2010; 23(66): 54-63.

30. Khaje Nasiri F. Prevalence of depression and its effective factors in nurses of Imam Khomeini Hospital in Tehran. Journal of Tehran University of Medical Sciences. 2000;58 (1): 10-14.

31. Chang E.M and et al. A survey of role stress, coping and health in Australian and New Zealand hospital nurses. International journal of nursing studies.2007; 44(8): 1354-1362.
32. K. Fatemeh, Mehmet N. Relationship between quality of sleep and quality of life of Nurses working in Shohadaye Kargar Hospital of Yazd, Iran. ESTÜDAM Halk Sağlığı Dergisi. 2020;5(3):401-9.

33. Badri M.A, Attia $S$ and Ustadi A.M. Healthcare quality and moderators of patient satisfaction: testing for causality. International journal of health care quality assurance. 2009. ISSN: 0952-6862. 